\title{
Lead Telluride Doped with Au as a Very Promising Material for Thermoelectric Applications
}

\author{
Pantelija M. Nikolic, ${ }^{1}$ Konstantinos M. Paraskevopoulos, ${ }^{2}$ \\ Triantafyllia T. Zorba, ${ }^{2}$ Zorka Z. Vasiljevic, ${ }^{1}$ Eleni Pavlidou, ${ }^{2}$ \\ Stevan S. Vujatovic, ${ }^{1}$ Vladimir Blagojevic, ${ }^{3}$ Obrad S. Aleksic, ${ }^{4}$ \\ Aleksandar I. Bojicic, ${ }^{1}$ and Maria V. Nikolic ${ }^{4}$ \\ ${ }^{1}$ Institute of Technical Sciences of SASA, Knez Mihailova 35/IV, 11000 Belgrade, Serbia \\ ${ }^{2}$ Physics Department, Solid State Section, Aristotle University of Thessaloniki, 54124 Thessaloniki, Greece \\ ${ }^{3}$ Faculty of Electrical Engineering, University of Belgrade, Bulevar Kralja Aleksandra 73, 11000 Belgrade, Serbia \\ ${ }^{4}$ Institute for Multidisciplinary Research, University of Belgrade, Kneza Viseslava 1, 11000 Belgrade, Serbia
}

Correspondence should be addressed to Pantelija M. Nikolic; pantelija.nikolic@sanu.ac.rs

Received 15 December 2014; Accepted 24 February 2015

Academic Editor: Sanjeeviraja Chinnappanadar

Copyright (C) 2015 Pantelija M. Nikolic et al. This is an open access article distributed under the Creative Commons Attribution License, which permits unrestricted use, distribution, and reproduction in any medium, provided the original work is properly cited.

\begin{abstract}
$\mathrm{PbTe}$ single crystals doped with monovalent $\mathrm{Au}$ or $\mathrm{Cu}$ were grown using the Bridgman method. Far infrared reflectivity spectra were measured at room temperature for all samples and plasma minima were registered. These experimental spectra were numerically analyzed and optical parameters were calculated. All the samples of PbTe doped with Au or Cu were of the " $n$ " type. The properties of these compositions were analyzed and compared with $\mathrm{PbTe}$ containing other dopants. The samples of PbTe doped with only 3.3 at\% $\mathrm{Au}$ were the best among the $\mathrm{PbTe}+\mathrm{Au}$ samples having the lowest plasma frequency and the highest mobility of free carriers-electrons, while $\mathrm{PbTe}$ doped with $\mathrm{Cu}$ was the opposite. Samples with the lowest $\mathrm{Cu}$ concentration of 0.23 at\% $\mathrm{Cu}$ had the best properties. Thermal diffusivity and electronic transport properties of the same PbTe doped samples were also investigated using a photoacoustic (PA) method with the transmission detection configuration. The results obtained with the far infrared and photoacoustic characterization of $\mathrm{PbTe}$ doped samples were compared and discussed. Both methods confirmed that when $\mathrm{PbTe}$ was doped with $3.3 \mathrm{at} \% \mathrm{Au}$, thermoelectric and electrical properties of this doped semiconductor were both significantly improved, so $\mathrm{Au}$ as a dopant in $\mathrm{PbTe}$ could be used as a new high quality thermoelectric material.
\end{abstract}

\section{Introduction}

Sixty-three years ago a new radio isotope was presented for the first time in Washington. A thermoelectric generator utilized the Seebeck effect of the semiconductor PbTe to convert radio isotope heat to electricity. Since then thermoelectric properties have been extensively studied all over the world $[1,2]$. Special attention has been paid to increase the thermoelectric figure of merit (ZT) for enabling the wide spread use of this method for directly converting heat into electricity [3]. PbTe and PbSnTe alloys have also been investigated for some time due to their unusual positive temperature coefficient of the energy gap [4-6] and that stimulated the current interest in these semiconductors also as materials for producing infrared detectors and light emitting devices [79]. These semiconducting materials are still permanently in focus and some new results on the electronic structure of both pure and doped semiconductors have been published [10-12].

The effect of doping $\mathrm{PbTe}$ with other elements has been studied extensively beginning with Rosenberg et al. [13]. Then, Weiser [14] started doping PbTe with group III elements (In, Al, Ga, and $\mathrm{Tl}$ ). Recently, some far infrared data of $\mathrm{PbTe}$ doped with the lightest element of this group III Boron has been reported by Nikolic et al. [15]. There it was shown that for a very small content of boron atoms (about 0.1 at $\%$ or less) PbTe was of the " $p$ " type with the lowest plasma frequency and the highest mobility of free carriers. 
Previously, Tetyorkin and Movchan have shown that when PbTe was doped with less than 0.1 at\% Ga, [16] it was of the " $p$ " type with the free carrier concentration of about $p \cong 10^{14} \mathrm{~cm}^{-3}$. But when there was more than 0.13 at $\%$ $\mathrm{Ga}$ in PbTe then they obtained " $n$ " type samples with an even lower free carrier concentration $\left(n \cong 10^{12} \mathrm{~cm}^{-3}\right)$. This behavior was supposed to be the result of compensation of the crystal structure defects by introducing the dopant atoms. Romcevic et al. [17] also reported that when $\mathrm{PbTe}$ was doped with less than 0.2 at\% Ga it was of the " $p$ " type, while a sample with 0.4 at $\% \mathrm{Ga}$ was of " $n$ " type. A similar change from " $p$ " to " $n$ " type of PbTe samples doped with 0.5 at $\%$ or 1.5 at\% Ce was also observed [18]. A number of studies have been published for various type of dopants in $\mathrm{PbTe}$ analyzing monovalent $(\mathrm{Na}, \mathrm{K}, \mathrm{Rb}, \mathrm{Cs}$, and $\mathrm{Cu})$ then divalent $(\mathrm{Zn}, \mathrm{Cd}$, and $\mathrm{Hg})$ and trivalent $(\mathrm{Ga}, \mathrm{In}$, and $\mathrm{Tl})$ impurities in $\mathrm{PbTe}$. The electronic structure of deep "defect" states in PbTe was studied by Ahmad et al. [19] where they, among other things, considered the case when in PbTe the lead atom was substituted by monovalent atoms (alkalis, $\mathrm{Cu}$ ). They focused their calculation on the electronic density of states (DOS) with and without defects. They concluded that alkali atoms and $\mathrm{Cu}$ also give rise to an increase in the DOS near the bottom of the conduction band.

Attention has also been paid to improvement of the thermoelectric performance of PbTeAgSe mixtures via $\mathrm{Cu}$ doping [20] but as far as we know nobody has considered the effect when $\mathrm{PbTe}$ was doped only with pure $\mathrm{Cu}$ or $\mathrm{Au}$. So in this work we investigated $\mathrm{PbTe}$ doped with a small percentage of $\mathrm{Au}$ or $\mathrm{Cu}$.

We compared the behavior of $\mathrm{Cu}$ as a dopant in $\mathrm{PbTe}$ with another monovalent metal, such as $\mathrm{Au}$. The behavior of PbTe doped with 0.3 at $\%$ or 3.3 at\% of Au was compared with $\mathrm{PbTe}$ doped with pure $\mathrm{Cu}$ and then discussed, taking account into "ab initio" studies of the electronic structure of defects in $\mathrm{PbTe}$ [19].

\section{Experimental}

Single crystal ingots of PbTe doped with 0.3 at $\%, 1.7$ at $\%$, and 3.3 at\% Au were synthesized using the Bridgman method as described in [21]. High purity elements $(6 \mathrm{~N})$ were used as the source material. The composition of Au decreased along the length of the ingot, because the factor of segregation was just above one, so samples with different gold contents could be cut and prepared for measurements. X-ray diffraction measurements proved that the obtained crystal ingots were single crystals, which could be cleaved perpendicular to the $c$ axis. We also doped PbTe samples with another monovalent element $\mathrm{Cu}$ making three small ingots of $\mathrm{PbTe}$ doped with $0.3 \mathrm{at} \%, 1.4 \mathrm{at} \%$, and $1.7 \mathrm{at} \% \mathrm{Cu}$. The content of $\mathrm{Pb}, \mathrm{Te}$, and $\mathrm{Cu}$ or $\mathrm{Au}$ in each sample was obtained using Energy Dispersive X-ray Spectroscopy (EDS) analysis on a JEOL JSM 6390 device equipped with an Oxford EDS analyzer. Measurements were made in the middle of the sample (as far infrared reflectivity is measured in the middle of the sample) and the surface area was measured in order to determine

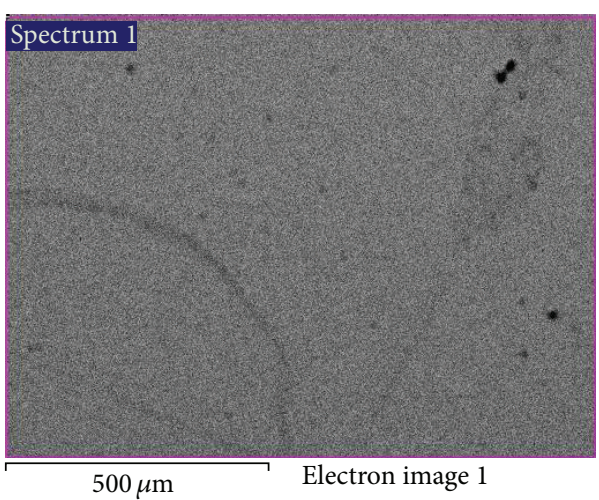

FIGURE 1: Scanning electron micrograph (SEM) of PbTe doped with 1.4 at $\% \mathrm{Cu}$ showing EDS sampling surface.

a mean content value. The maximum aperture was $1 \mathrm{~mm} \times$ $1 \mathrm{~mm}$. An example of EDS measurements is given in Figure 1.

Far infrared reflectivity (FIR) spectra of all PbTe sample doped with $\mathrm{Au}$ or $\mathrm{Cu}$ were measured at room temperature using a Bruker IFS-113 V spectrometer. Using the "hot spot" method it was proved that all $\mathrm{PbTe}+\mathrm{Au}$ and $\mathrm{PbTe}+\mathrm{Cu}$ samples were of the " $n$ " type.

Since the sample of PbTe doped with the smallest percentage of $\mathrm{Cu}$ had the lowest plasma frequency and the highest mobility of the free carriers-electrons, while the PbTe samples doped with Au behaved the opposite, we also investigated the thermal diffusivity and electron transport properties of all the PbTe doped samples using a photoacoustic (PA) method with the transmission detection configuration which confirmed the different behavior of PbTe doped with $\mathrm{Au}$ or $\mathrm{Cu}$.

\section{Results and Discussion}

Far infrared reflectivity diagrams for $\mathrm{PbTe}$ doped with $\mathrm{Au}$ were measured for three compositions: $\mathrm{PbTe}$ doped with 0.3 at $\%, 1.7$ at $\%$, and 3.3 at $\%$ Au are given in Figure 2. The lowest plasma frequency was observed unexpectedly for the sample with $3.3 \mathrm{at} \% \mathrm{Au}$, the highest percentage of $\mathrm{Au}$, quite opposite compared with $\mathrm{PbTe}$ doped with $\mathrm{Cu}$. All these samples were of the " $n$ " type.

The measured far infrared reflectivity spectra of single crystal PbTe doped with $0.29,0.24$, and 0.23 at $\% \mathrm{Cu}$ are shown in Figure 3. They all have relatively sharp minimum at about $120 \mathrm{~cm}^{-1}$. Figure 4 contains reflectivity diagrams of PbTe samples with higher amounts of $\mathrm{Cu}$, between 1.4 at $\% \mathrm{Cu}$ and 1.7 at $\% \mathrm{Cu}$. Analysis of the optical reflectivity diagrams given in these two figures indicate that the first three samples (Figure 3) have relatively sharp and stable plasma minimum, while for samples with a much higher percentage of $\mathrm{Cu}$ (above 1.4 at\%) given in Figure 4, the plasma minima has moved to much higher wave numbers, about $450 \mathrm{~cm}^{-1}$, because the quality of the samples with the increased content of $\mathrm{Cu}$ was decreased a lot.

All the experimental reflectivity spectra were numerically analyzed using a modified four parameter model for 


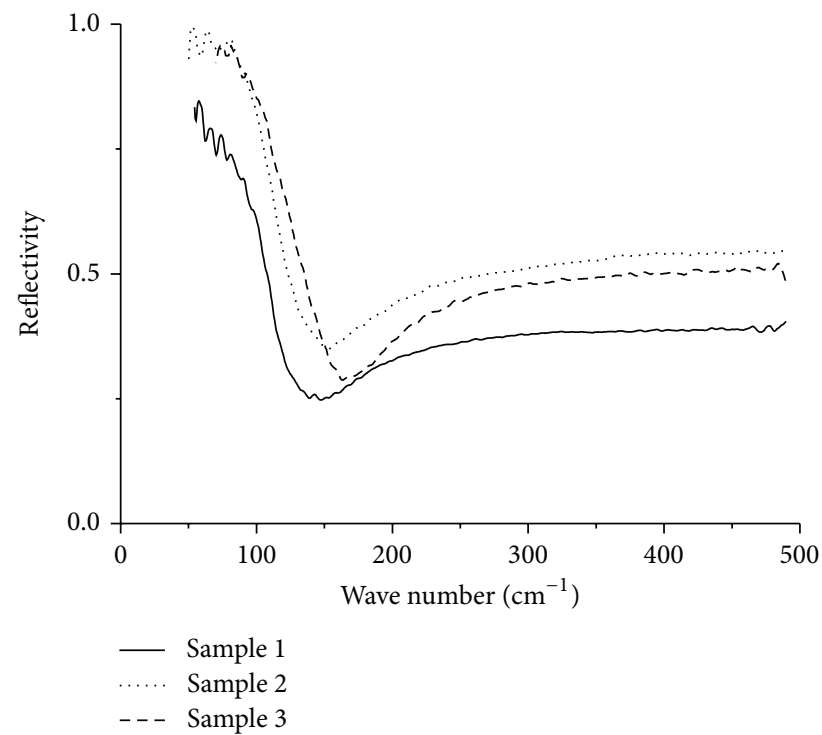

FIGURE 2: Room temperature FIR diagrams of $\mathrm{PbTe}$ doped with 3.3 at\% Au (Sample 1, "beginning"), 1.7 at\% Au (Sample 2, "middle"), and 0.3 at\% Au (Sample 3, "end").

the dielectric function [22] taking into account the influence of the plasma mode of the free carriers [23]:

$$
\begin{aligned}
\varepsilon(\omega)= & \varepsilon_{\infty} \frac{\prod_{j=1}^{2}\left(\omega^{2}+i \gamma_{l j} \omega-\omega_{l j}^{2}\right)}{\omega\left(\omega+i \gamma_{p}\right)\left(\omega^{2}+i \gamma_{t} \omega-\omega_{t}^{2}\right)} \\
& \cdot \prod_{n=1}^{p} \frac{\omega^{2}+i \gamma_{L n} \omega-\omega_{L n}^{2}}{\omega^{2}+i \gamma_{0 n} \omega-\omega_{0 n}^{2}} \\
& \cdot \prod_{k=1}^{q} \frac{\omega^{2}+i \gamma_{\mathrm{LO} k} \omega-\omega_{\mathrm{LO} k}^{2}}{\omega^{2}+i \gamma_{\mathrm{TO} k} \omega-\omega_{\mathrm{TO} k}^{2}}
\end{aligned}
$$

where $\omega_{t}$ is the transverse phonon frequency and $\omega_{l j}$ and $\gamma_{l j}$ are parameters of the first numerator representing eigenfrequencies and damping factor of the plasmon-LO phonon waves, respectively. First denominator parameters correspond to similar characteristics of the transverse vibrations. $\gamma_{p}$ is the plasmon mode damping factor and $\varepsilon_{\infty}$ represents the high frequency dielectric permittivity relative to the spectral interval of interest. The second term represents local impurity modes, while in the third term $\omega_{\mathrm{LO} k}, \omega_{\mathrm{TO} k}, \gamma_{\mathrm{LO} k}$, and $\gamma_{\mathrm{TO} k}$ represent longitudinal and transverse frequencies and damping factors of the host crystal uncoupled modes. The starting values of the parameters used in the fitting procedure were previously obtained using Kramers-Krönig analysis [24]. As the reflectivity spectra were measured down to $50 \mathrm{~cm}^{-1}$, the value for the transverse phonon frequency, $\omega_{t}$ was taken from literature to be $32 \mathrm{~cm}^{-1}$ [17]. The values for the plasmon frequency $\left(\omega_{p}\right)$ were determined using the extended Lyddane-Sachs-Teller (LST) relation introduced by Kukharskii [23]:

$$
\omega_{p}=\frac{\omega_{l 1} \cdot \omega_{l 2}}{\omega_{t}}
$$

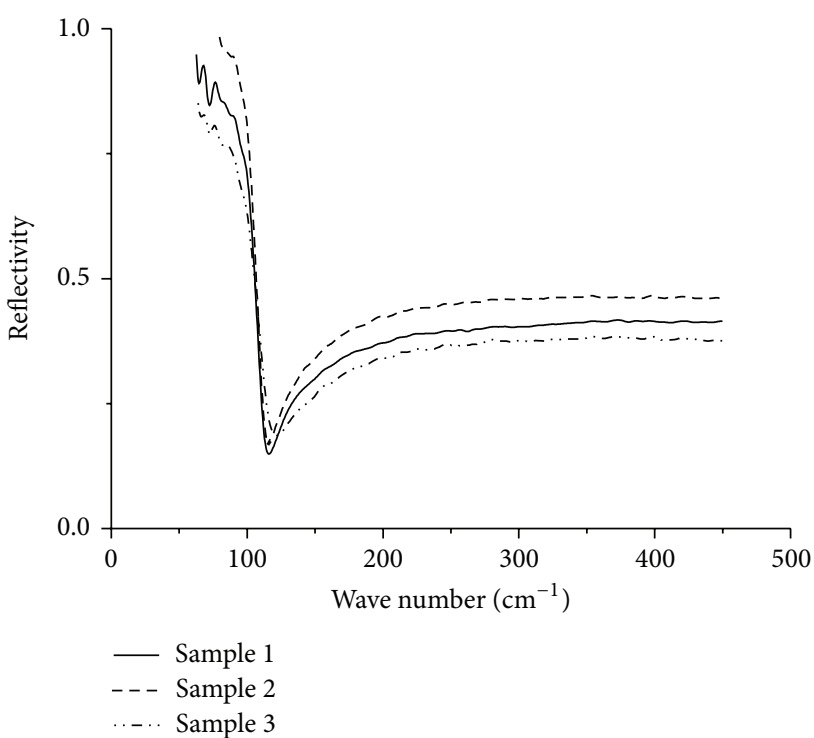

FIGURE 3: Room temperature FIR diagrams of $\mathrm{PbTe}$ doped with 0.29 at\% Cu (Sample 1, "beginning"), 0.24 at\% Cu (Sample 2, "middle"), and 0.23 at\% Cu (Sample 3, "end")—first ingot.

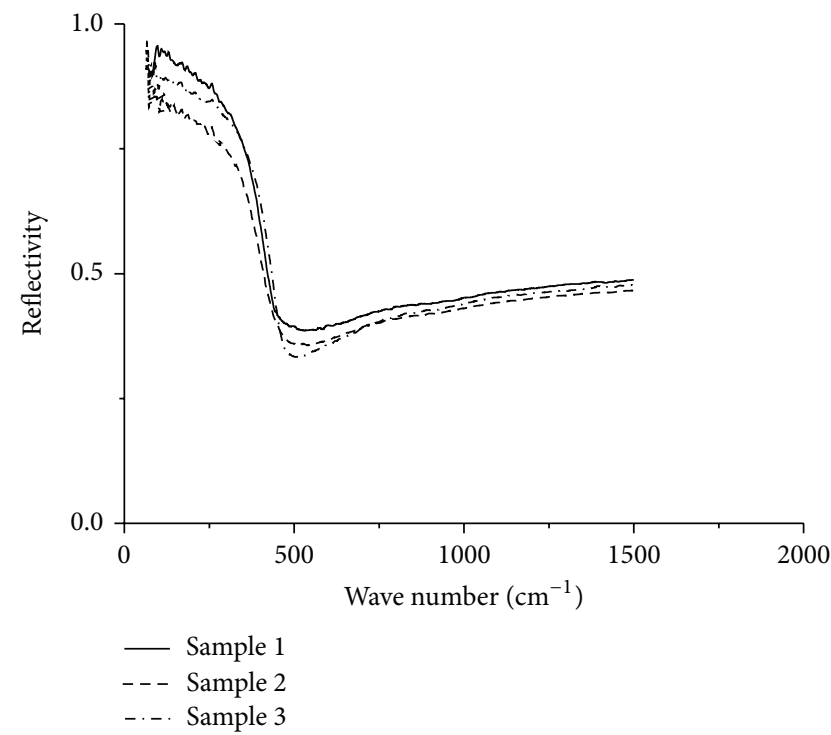

FIGURE 4: Room temperature FIR diagrams of PbTe doped with 1.7 at\% $\mathrm{Cu}$ (Sample 1, "beginning"), 1.6 at\% Cu (Sample 2, "middle"), and 1.4 at\% $\mathrm{Cu}$ (Sample 3, "end")—-second ingot.

The values of parameters determined for three samples of $\mathrm{PbTe}$ doped with Au are given in Table 1 . They are $\omega_{p}$, plasma frequency; its damping factor, $\gamma_{p} ; R_{\min }$, optical reflectivity coefficient at plasma frequency; the optical mobility of free carriers $\left(\mu_{n}\right)$, and the majority free carrier concentrations, $(n)$ in this case the free electron concentration which was calculated using the method of Moss et al. [25].

The values of the parameters calculated for $\mathrm{PbTe}$ doped with $\mathrm{Cu}$, using our fitting procedure, are given in Tables 2 and 3. Analysis of the parameter values presented in Table 2 enable the conclusion that samples of PbTe doped with 
TABle 1: Calculated parameters for PbTe doped with Au.

\begin{tabular}{lccccc}
\hline $\mathrm{PbTe}+\mathrm{Au}$ & $\omega_{p}\left(\mathrm{~cm}^{-1}\right)$ & $\gamma_{p}\left(\mathrm{~cm}^{-1}\right)$ & $R_{\min }$ & $\mu_{n}\left(\mathrm{~cm}^{2} / \mathrm{Vs}\right)$ & $n\left(\mathrm{~cm}^{-3}\right)$ \\
\hline Sample 1 & 125.5 & 39.5 & 0.27 & 2142 & $9.10 \times 10^{17}$ \\
Sample 2 & 136.6 & 48.0 & 0.33 & 1612 & $1.04 \times 10^{18}$ \\
Sample 3 & 153.4 & 47.0 & 0.29 & 1450 & $1.5 \times 10^{18}$ \\
\hline
\end{tabular}

TABle 2: Calculated parameters for PbTe doped with $\mathrm{Cu}$ (first ingot).

\begin{tabular}{lccccc}
\hline $\mathrm{PbTe}+\mathrm{Cu}$ (first ingot) & $\omega_{p}\left(\mathrm{~cm}^{-1}\right)$ & $\gamma_{p}\left(\mathrm{~cm}^{-1}\right)$ & $R_{\min }$ & $\mu_{n}\left(\mathrm{~cm}^{2} / \mathrm{Vs}\right)$ & $n\left(\mathrm{~cm}^{-3}\right)$ \\
\hline Sample 1 (beginning) & 111.5 & 14.4 & 0.15 & 3431 & $6.8 \times 10^{17}$ \\
Sample 2 (middle) & 114.5 & 21.1 & 0.18 & 3770 & $7.3 \times 10^{17}$ \\
Sample 3 (end) & 110.8 & 11.3 & 0.17 & 4571 & 0.29 \\
\hline
\end{tabular}

TABLE 3: Calculated parameters for PbTe doped with $\mathrm{Cu}$ (second ingot).

\begin{tabular}{lccccc}
\hline PbTe + Cu (second ingot) & $\omega_{p}\left(\mathrm{~cm}^{-1}\right)$ & $\gamma_{p}\left(\mathrm{~cm}^{-1}\right)$ & $R_{\min }$ & $\mu_{n}\left(\mathrm{~cm}^{2} / \mathrm{Vs}\right)$ & $n\left(\mathrm{~cm}^{-3}\right)$ \\
\hline Sample 1 $(\mathrm{PbTeCu}, \mathrm{a})$ & 440.0 & 160.0 & 0.38 & 61 & $4.0 \times 10^{19}$ \\
Sample 2 $(\mathrm{PbTeCu}, \mathrm{b})$ & 443.0 & 183.0 & 0.36 & 52 & $6.4 \times 10^{19}$ \\
Sample 3 $(\mathrm{PbTeCu}, \mathrm{c})$ & 457.0 & 125.0 & 0.33 & 71 & 1.6 \\
\hline
\end{tabular}

0.23 at $\% \mathrm{Cu}$ have the lowest plasma frequency, the highest mobility of free carriers-electrons, of $4571 \mathrm{~cm}^{2} / \mathrm{Vs}$, and the lowest free carrier concentration-electrons $\left(6.3 \times 10^{17} \mathrm{~cm}^{-3}\right)$.

The high value of free carrier mobility and decrease of their concentration when $\mathrm{PbTe}$ is doped with a very low $\mathrm{Cu}$ concentration $(0.23$ at $\%-0.29$ at $\%)$ is indication that this could be the result of compensation of crystal structure defects by introducing a suitable percentage of dopant atoms. Then, $\mathrm{Cu}$ atoms could fill lead atom vacancies. Looking at the properties of $\mathrm{PbTe}+\mathrm{Cu}$ samples doped with 1.4 at $\% \mathrm{Cu}$ or more, given in Table 3, one can see that the plasma frequency is about four times higher and the free carriers mobility is about 50 times smaller compared with the samples of PbTe doped with less than 0.3 at\% $\mathrm{Cu}$. So, one can suppose that some $\mathrm{Cu}$ atoms get into interstitial positions. Then, the space distribution of the impurity could be observed by atomic and electron microscopy.

With the intention to get more useful data for discussion about the properties of our PbTe samples doped with $\mathrm{Au}$ or $\mathrm{Cu}$, we also calculated the optical conductivity and the reciprocal values of imaginary part of dielectric constant $[\operatorname{Im}(1 / \varepsilon)]$ versus the wave number in the whole range of the measured optical reflectivity spectra. Figure 5 gives these diagrams for the sample doped with 0.23 at\% $\mathrm{Cu}$ together with its optical reflectivity diagrams Figure 5(a) where the minimum is at about $120 \mathrm{~cm}^{-1}$. The optical conductivity Figure 5(b) also has a slightly less exposed minimum in the similar range while $\operatorname{Im}(1 / \varepsilon)$, Figure $5(\mathrm{c})$ has a sharp maximum at about $113 \mathrm{~cm}^{-1}$ with its half height width of about $25 \mathrm{~cm}^{-1}$.

The same diagrams were calculated and given in Figures 6(a)-6(c), for the PbTe sample doped with a much higher percentage of $\mathrm{Cu}(1.4$ at $\%)$, and the calculated parameters are given in Table 3. Comparing Figures 5 and 6, we can see that for these two samples doped with 0.23 at $\% \mathrm{Cu}$ and 1.4 at $\%$ $\mathrm{Cu}$, the positions of minima for the optical conductivity and real part of refraction get increased about four times when the atomic percent of $\mathrm{Cu}$ in $\mathrm{PbTe}$ was increased for about 5.8 times. Also the position of maximum of the reciprocal values of imaginary part of dielectric constant $\operatorname{Im}(1 / \mathcal{\varepsilon})$ was increased from about $113 \mathrm{~cm}^{-1}$ to more than $455 \mathrm{~cm}^{-1}$, with increased half hight width for about four times. Similarly, plasma frequency calculated for these two samples, given in Tables 2 and 3, increases from $110.8 \mathrm{~cm}^{-1}$ to $457 \mathrm{~cm}^{-1}$.

When $\mathrm{PbTe}$ was doped with $\mathrm{Au}$, the opposite results compared to $\mathrm{PbTe}$ doped with $\mathrm{Cu}$ were obtained. The sample with the highest content of $\mathrm{Au}$ (3.3 at\%) had the lowest plasma frequency (Figure 7) and the sample with the smallest content of $\mathrm{Au}(0.3 \mathrm{at} \%)$ has the highest plasma frequency (Figure 8 ). Similar differences were obtained for the calculated diagrams of optical conductivity and the reciprocal values of the imaginary part of the dielectric constant $[\operatorname{Im}(1 / \varepsilon)]$ versus the wave number, Figures 7(c) and 8(c).

To analyse and confirm this very important property of PbTe doped with $\mathrm{Au}$, we also measured the photoacoustic properties of PbTe samples doped with $\mathrm{Au}$ and $\mathrm{Cu}$. Amplitude and phase spectra of PbTe doped with 1.7 at $\%$ $\mathrm{Au}$ were measured using a high quality photoacoustic (PA) cell which had an optimized acoustic protection from the surrounding influence [26]. The optical source was a red laser $(80 \mathrm{~mW})$ modulated with a mechanical chopper and the sample, mounted on the front of the electrets microphone, was irradiated by a red spot, $2 \mathrm{~mm}$ in diameter. The amplitude and phase were measured for two thicknesses 


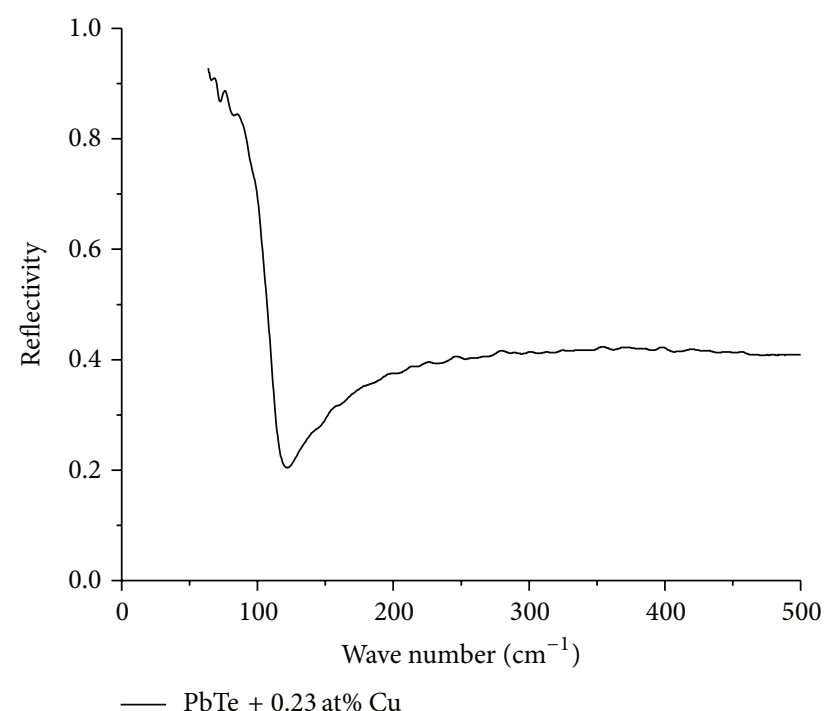

(a)

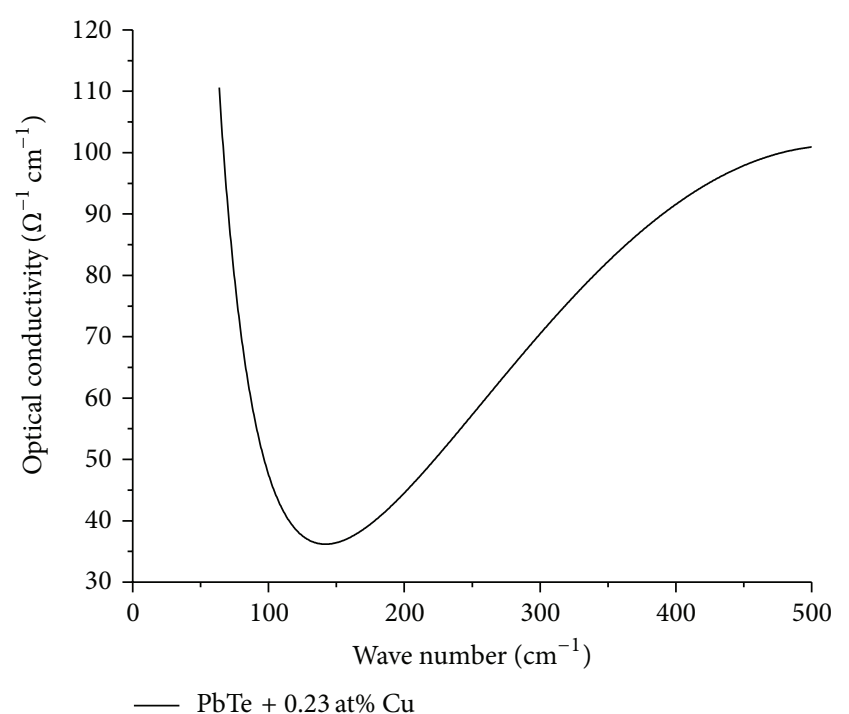

(b)

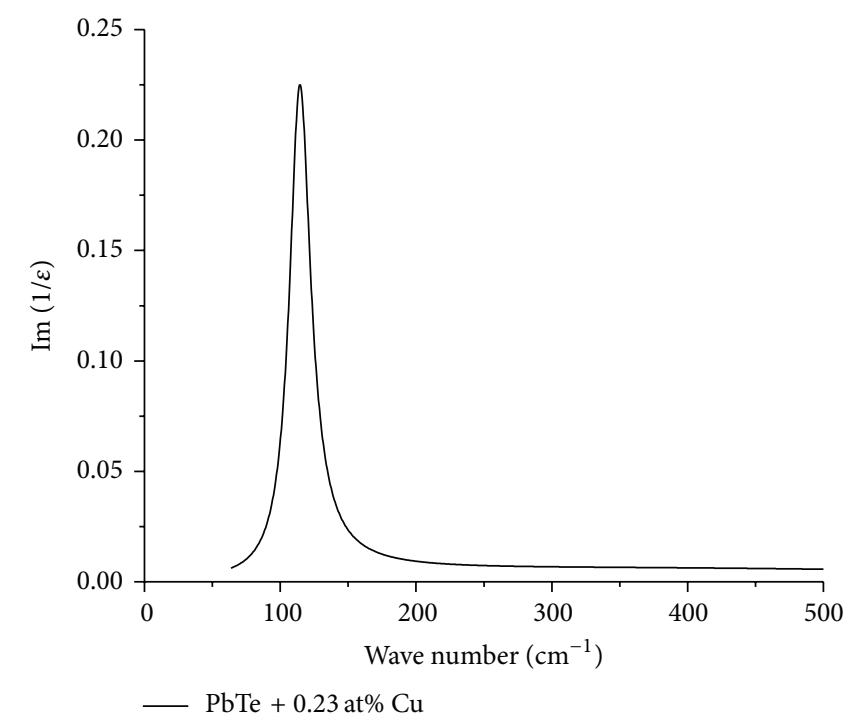

(c)

Figure 5: (a) Optical reflectivity diagram for PbTe doped with 0.23 at\% $\mathrm{Cu}$, (b) its optical conductivity, and (c) reciprocal values of imaginary part of dielectric constant $[\operatorname{Im}(1 / \varepsilon)]$.

of the same sample versus the modulation frequency. The different thicknesses of the same sample were obtained by polishing one side of the thick plate with diamond paste and the other side was only flattened with silicon carbide of $1 \mu \mathrm{m}$ grade and made it thinner. That surface was illuminated with the modulated laser beam while the side which was polished with the diamond paste and was put on the front of the electret microphone. The measured amplitude and phase PA signals versus the modulation frequency for PbTe doped with 1.7 at\% Au are given in Figures 9(a) and 9(b), respectively. These measurements for two samples thickness were used to normalize the PA amplitude and phase spectra as the sensitivity of the electrets microphone decrease in the frequency range below $100 \mathrm{~Hz}$ so we used the signal ratio for two different thicknesses of each measured sample. Starting with the Rosencwaig and Gershow, thermal piston model [27] the PA signal could be given with the following equation:

$$
S(-l, \omega)=\gamma \frac{P_{0} \Phi(-l, \omega)}{T_{0} K_{l} l_{b}}
$$

where $\gamma$ is the adiabatic constant and $P_{0}$ and $T_{0}$ the ambient pressure and temperature, respectively; $K_{l}=(1+j) / \mu_{b}$, where $\mu_{b}$ is the thermal diffusion length of the backing gas and $l_{b}$ is the distance between the sample and the microphone. $\Phi(-l, \omega)$ is the periodic temperature variation of the rear sample surface. 


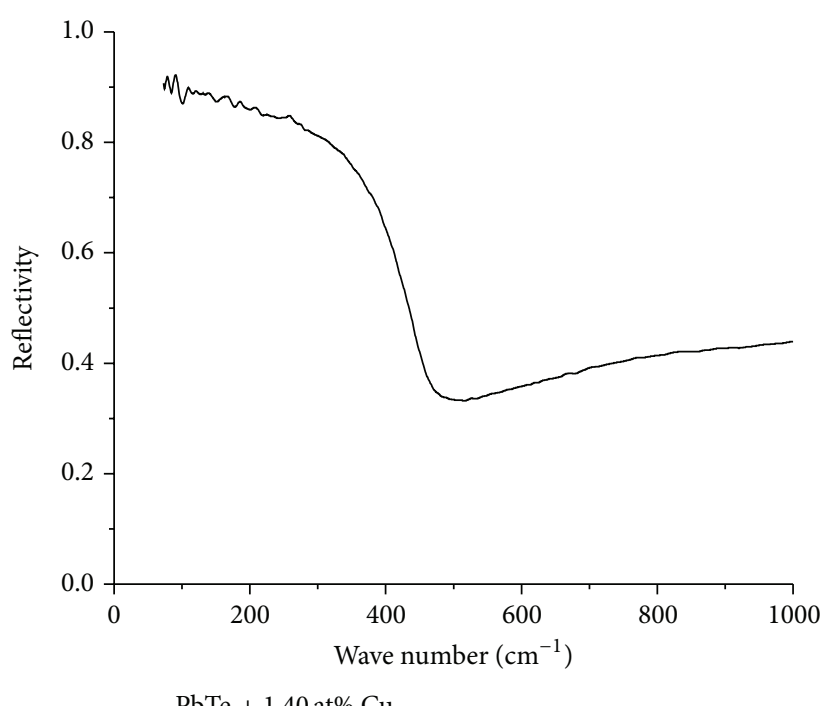

(a)

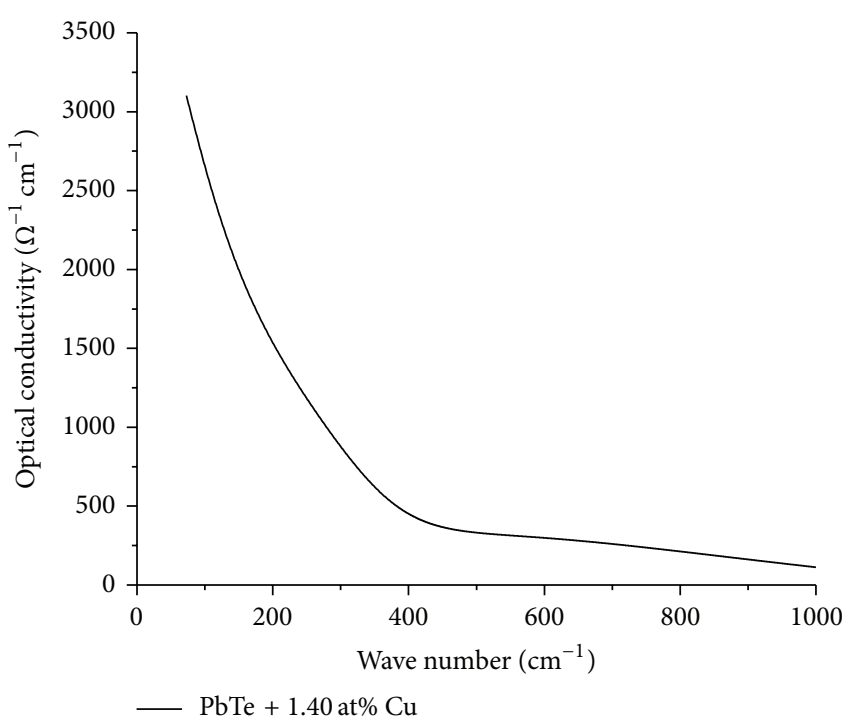

(b)

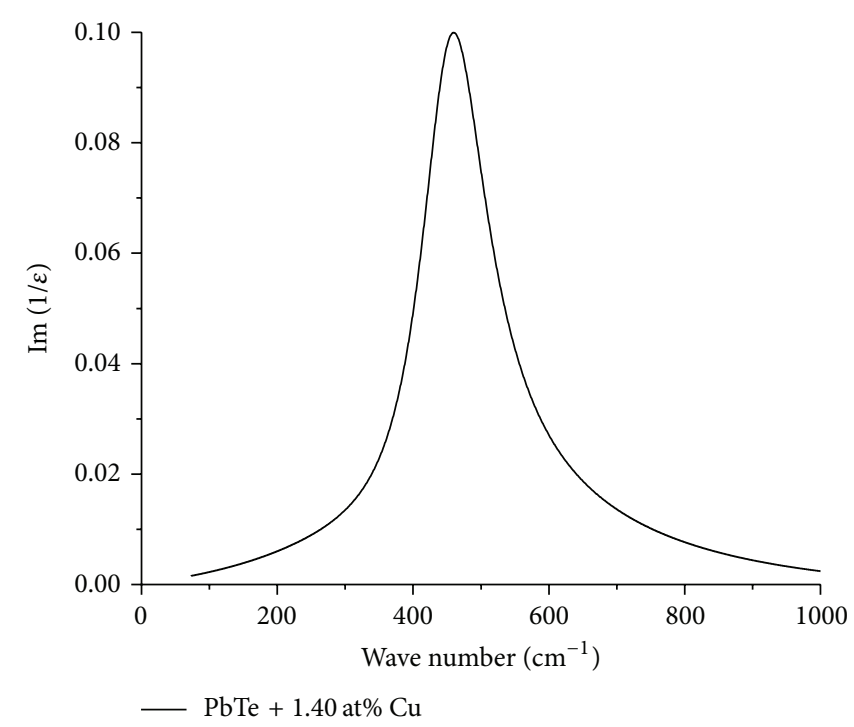

(c)

Figure 6: (a) Optical reflectivity diagram for PbTe doped with 1.4 at\% $\mathrm{Cu}$, (b) its optical conductivity, and (c) reciprocal values of imaginary part of dielectric constant $[\operatorname{Im}(1 / \varepsilon)]$.

Finally, the PA signal for two measurements and two different sample thicknesses can be normalized using the signal ratio and the equation:

$$
\frac{S_{1}(\omega)}{S_{2}(\omega)}=\left[\frac{\Phi\left(-l_{1}\right)}{\Phi\left(-l_{2}\right)}\right] e^{\left[j\left(\varphi_{1}\left(-l_{1}\right)-\varphi_{2}\left(-l_{2}\right)\right)\right]}=A_{m} e^{j \Delta \varphi},
$$

where $\Phi(-l)$ is the temperature distribution on the surface of the sample which was put in the contact with the electrets microphone; $A_{m}$ is the amplitude ratio and $\Delta \varphi$ is the phase difference of the measured PA signals for two different sample thicknesses.

The amplitude ratio and phase difference of fitted photoacoustic diagrams for the sample of PbTe doped with 1.7 at $\%$ $\mathrm{Au}$ and its two different thicknesses for the normalized PA spectra are given in Figures 10(a) and 10(b). Similarly, for $\mathrm{PbTe}$ doped with $1.7 \mathrm{at} \% \mathrm{Cu}$, the measured amplitude and phase PA signals versus the modulation frequency for two sample thicknesses are given in Figures 11(a) and 11(b), while the amplitude ratio and phase difference of fitted diagram are given in Figures 12(a) and 12(b). The values of fitted parameters for the normalised PA spectra are given in Table 4 for both $\mathrm{PbTe}$ doped with $1.7 \mathrm{at} \% \mathrm{Au}$ and $1.7 \mathrm{at} \% \mathrm{Cu}$ and they are the thermal diffusion coefficient $\left(D_{T}\right)$ the excess carrier life time $(\tau)$, the hole diffusion coefficient $(D)$, optical absorption coefficient $(\alpha)$, and also the calculated mobility of the hole carrier $\left(\mu_{h}\right)$.

Judging by the results for $\mathrm{PbTe}$ with either $1.7 \mathrm{at} \% \mathrm{Au}$ or $\mathrm{Cu}$ it is obvious that such a big quantity of $\mathrm{Au}$ in $\mathrm{PbTe}$ increases the mobility of that sample while if $\mathrm{PbTe}$ is doped 
TABLE 4: Fitted photoacoustic parameters for PbTe doped with 1.7 at $\% \mathrm{Au}$ or $\mathrm{Cu}$.

\begin{tabular}{|c|c|c|c|c|c|}
\hline & $D_{T}\left(\mathrm{~m}^{2} / \mathrm{s}\right)$ & $D\left(\mathrm{~m}^{2} / \mathrm{s}\right)$ & $\alpha\left(\mathrm{m}^{-1}\right)$ & $\tau(\mathrm{s})$ & $\mu_{n}\left(\mathrm{~cm}^{2} / \mathrm{Vs}\right)$ \\
\hline Sample $1(\mathrm{PbTe}+1.7 \mathrm{at} \% \mathrm{Au})$ & $0.1301 \times 10^{-5}$ & $0.110 \times 10^{-1}$ & 34144 & $0.791 \times 10^{-2}$ & 4263 \\
\hline Sample $2(\mathrm{PbTe}+1.7 \mathrm{at} \% \mathrm{Cu})$ & $0.1928 \times 10^{-5}$ & $0.133 \times 10^{-3}$ & 7914 & $0.589 \times 10^{-1}$ & 51 \\
\hline
\end{tabular}

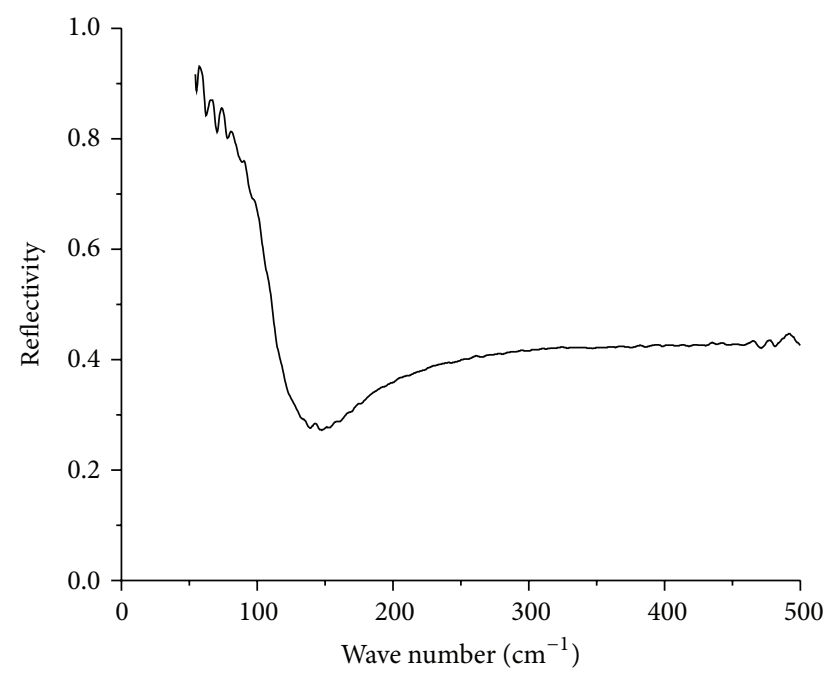

$\mathrm{PbTe}+3.3 \mathrm{at} \% \mathrm{Au}$

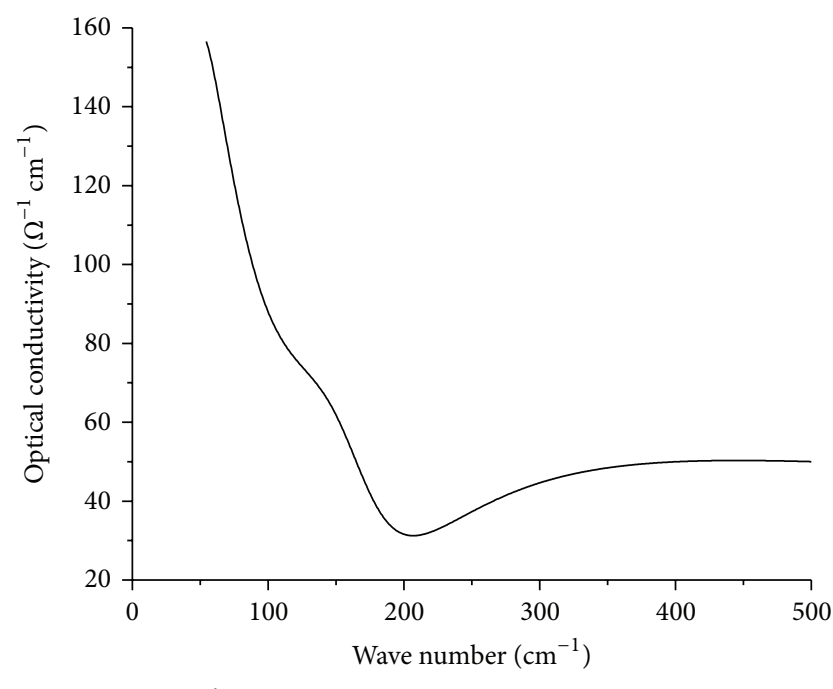

(b)

(a)

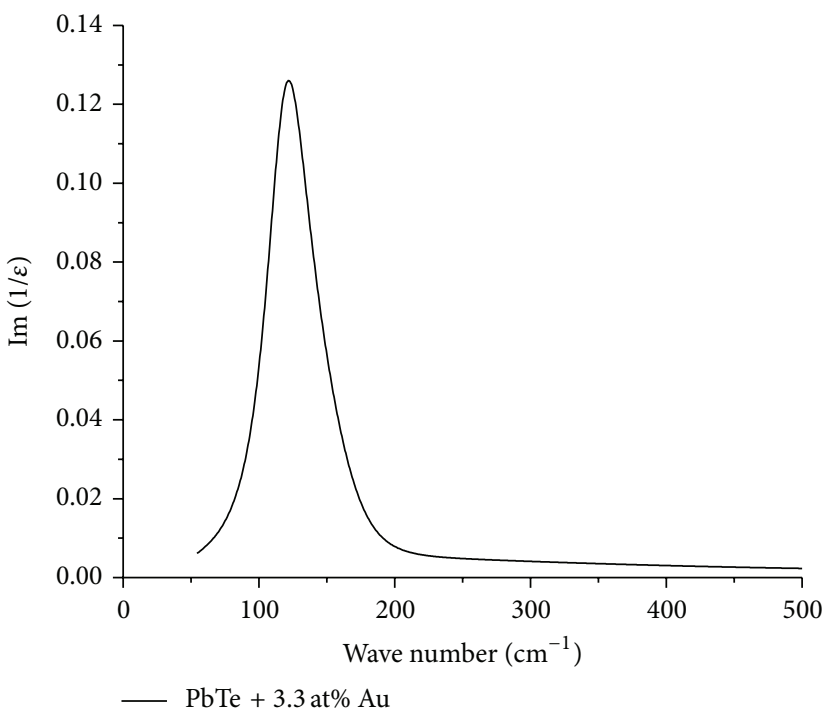

(c)

FiguRE 7: (a) Optical reflectivity diagram for PbTe doped with 3.3 at\% Au, (b) its optical conductivity, and (c) reciprocal value of imaginary part of dielectric constant $[\operatorname{Im}(1 / \varepsilon)]$.

with also 1.7 at $\% \mathrm{Cu}$, the mobility gets very decreased $(\mu$ gets decreased to the value of only 51 while for PbTe doped with 1.7 at $\% \mathrm{Au}, \mu$ increases to above $4263 \mathrm{~cm}^{2} / \mathrm{Vs}$. Similarly, thermal diffusivity is quite different for these two dopants: for 1.7 at $\% \mathrm{Au}, D_{T}$ is $0.1301 \times 10^{-5}$ and for 1.7 at $\% \mathrm{Cu}$. $D_{T}$ is higher: $0.1928 \times 10^{-5} \mathrm{~m}^{2} / \mathrm{s}$ ).
Since the diffusion coefficient, $D$, of the free carriers was about 80 times bigger for PbTe doped with 1.7 at\% Au than with $\mathrm{Cu}$, the calculated mobility was also similar showing that some very unusual effect producing these differences must be present. The excess carrier lifetime, $\tau$, the thermal diffusivity coefficient $\left(D_{T}\right)$, and optical absorption coefficient 


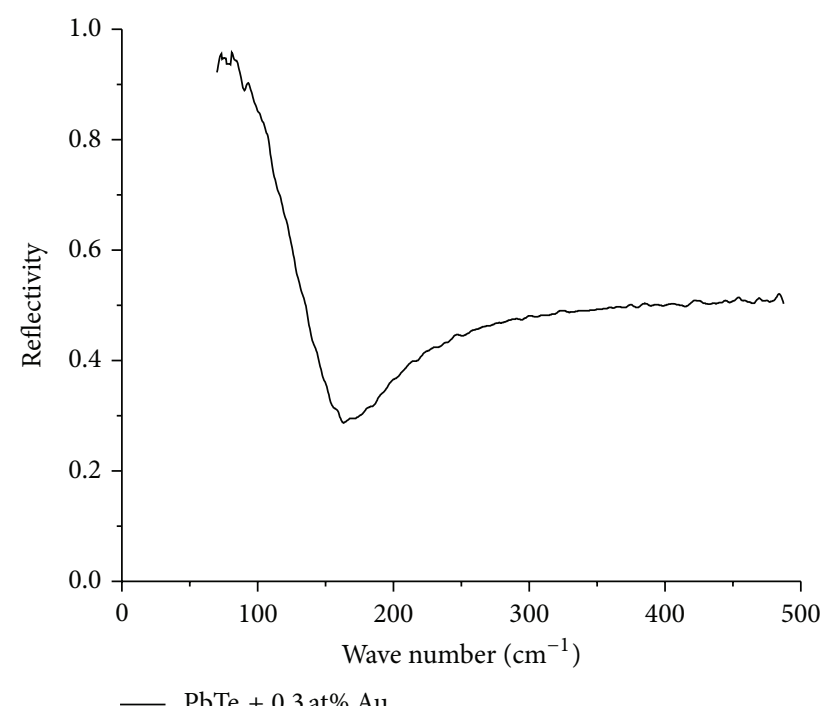

(a)

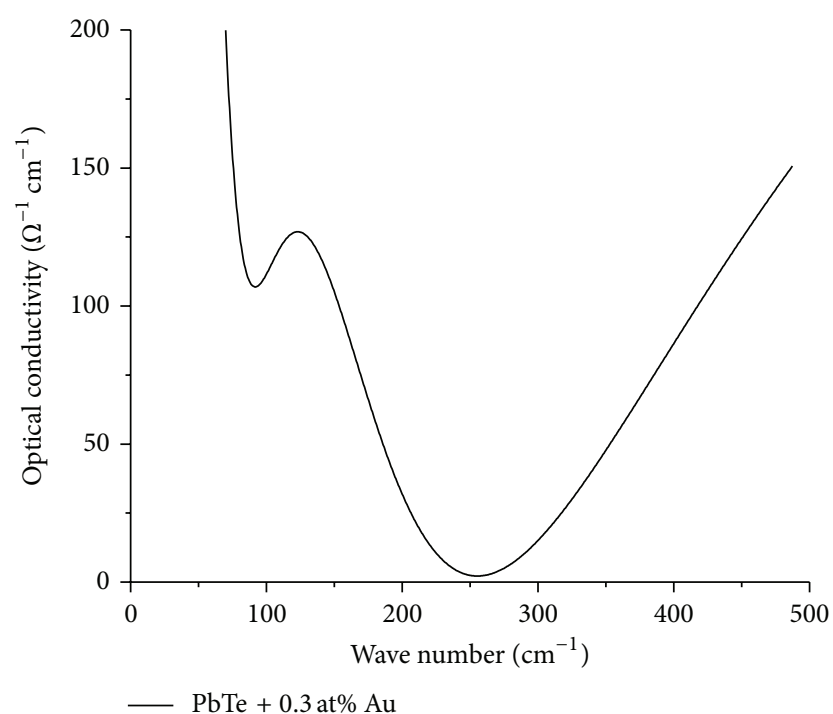

(b)

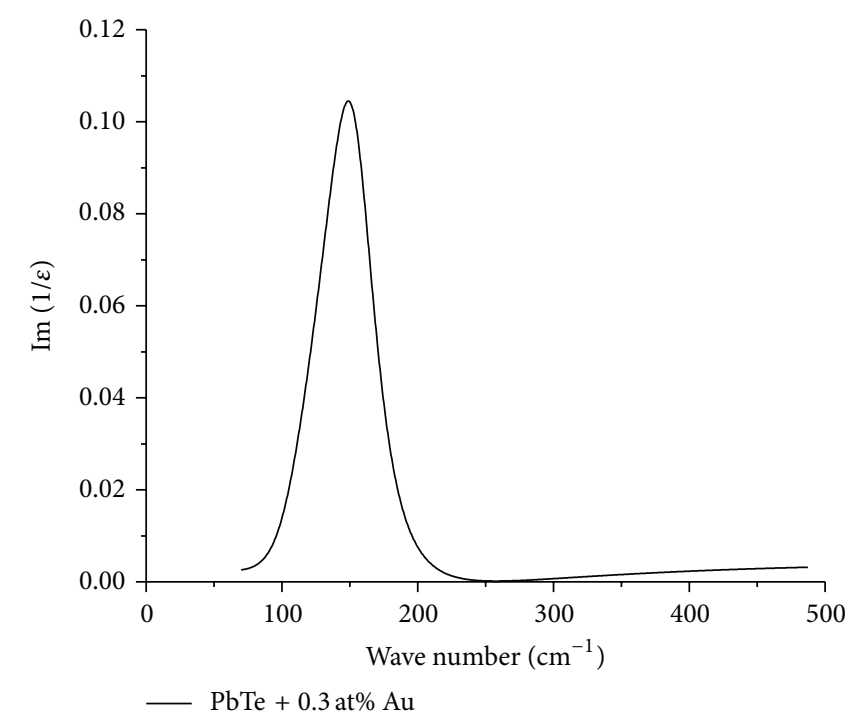

(c)

Figure 8: (a) Optical reflectivity diagram for PbTe doped with 0.3 at\% Au, (b) its optical conductivity, and (c) reciprocal value of imaginary part of dielectric constant $[\operatorname{Im}(1 / \varepsilon)]$.

differences for those two dopants confirm that Au as a dopant in $\mathrm{PbTe}$ behaves very differently compared with $\mathrm{Cu}$.

It is very important to consider why the samples doped with a higher quantity of $\mathrm{Au}$ are improving their properties in an opposite way compared with $\mathrm{PbTe}$ doped with $\mathrm{Cu}$.

Analyzing Table 1, one can see that when $\mathrm{PbTe}$ is doped with $3.3 \mathrm{at} \% \mathrm{Au}$ it has the highest value of the free electron mobility and the lowest free carrier electron concentration and the lowest plasma minimum. On the contrary, when the plasma minima were at $153.4 \mathrm{~cm}^{-1}$ for 0.3 at $\%$ Au the electron mobility was the smallest and the free carrier concentration the highest, about $1.5 \times 10^{18} \mathrm{~cm}^{-3}$.

In literature [28], it has been shown that PbSe doped with $\mathrm{Au}$ is a good candidate for $p$-type thermoelectric materials because of resonance states and a local increase of DOS compared with $\mathrm{PbSe}$ doped with $\mathrm{Na}$. There it was also concluded that the effects of the same impurity in PbSe and $\mathrm{PbTe}$ are very similar. This is proved in this work with the results obtained with the measurements of FIR and photoacoustic properties for PbTe doped with Au. An enhancement in the thermoelectric properties is observed similar in nature to what might be expected from resonance levels and that it is attributed to the behavior of the heavyhole valence band which corresponds to the lattice expansion and can be controlled to a significant degree by adjusting the Fermi energy. This causes the heavy-hole valence band to rise in energy and adjust the Fermi energy creating a significant enhancement in the DOS that gives rise to interband scattering having positive effects on the thermoelectric power factor. One also should take care that the effectiveness of a resonant 


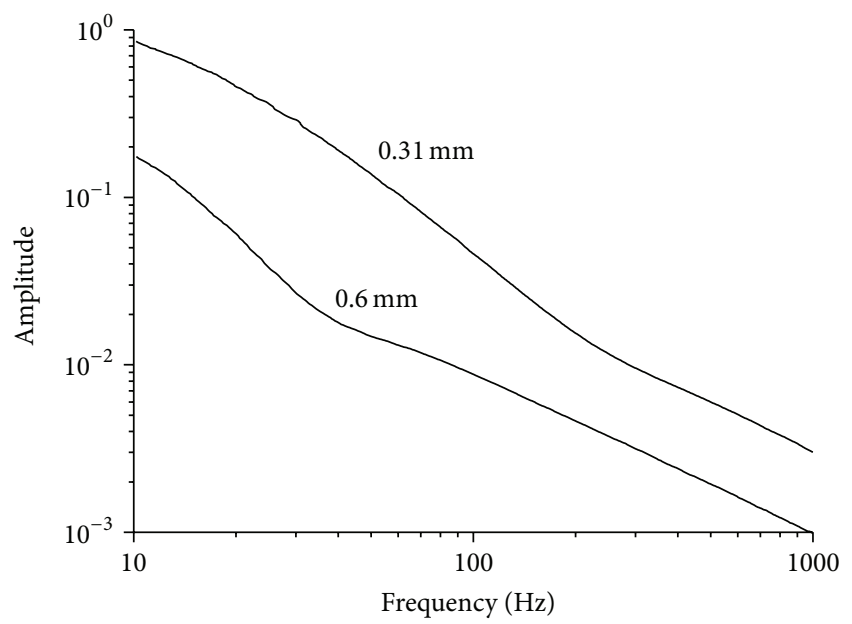

(a)

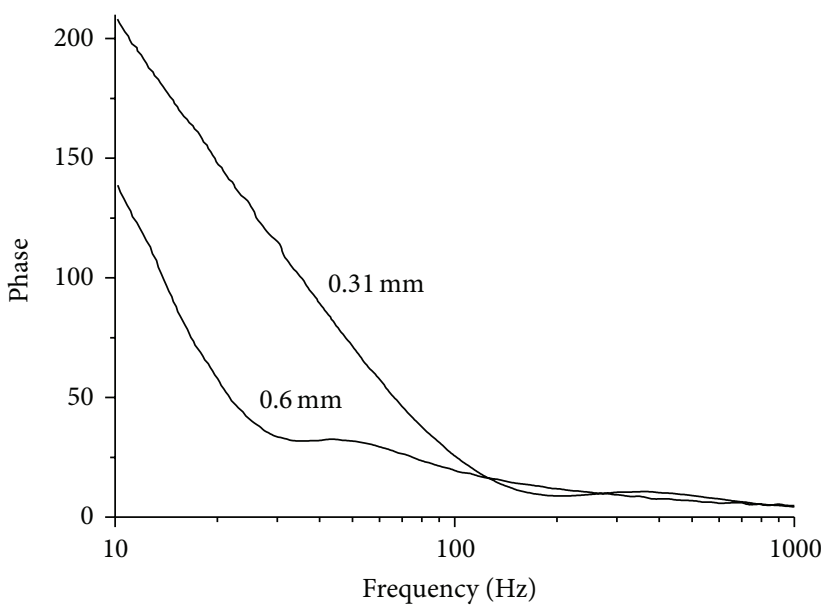

(b)

FIgUre 9: PA amplitude (a) and phase spectra (b) for PbTe doped with 1.7 at $\%$ Au for two different sample thicknesses.

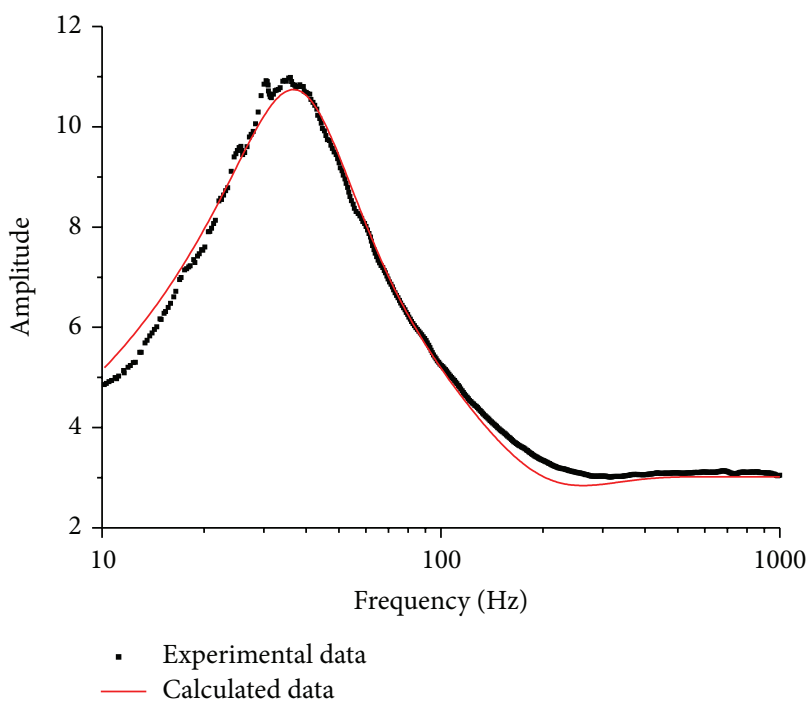

(a)

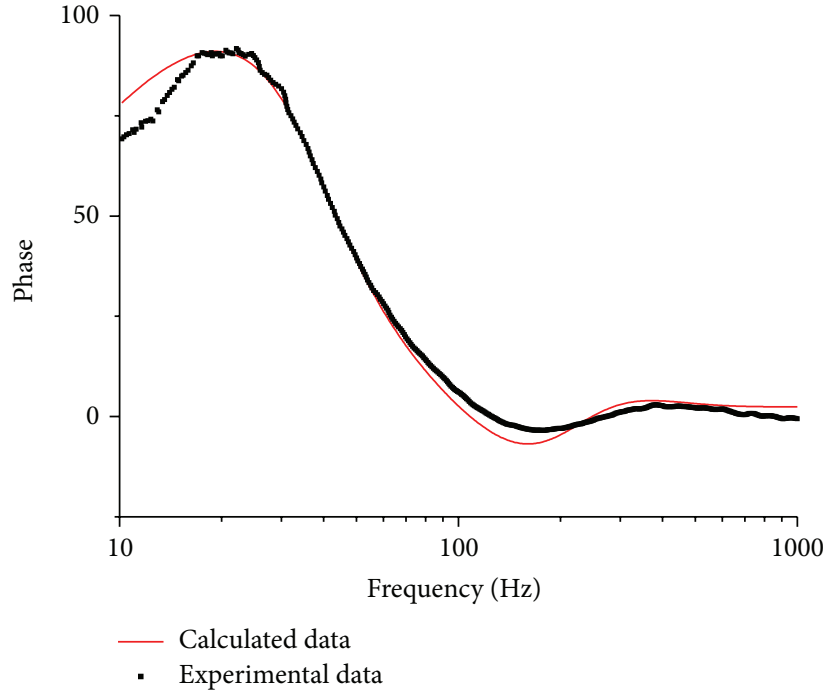

(b)

Figure 10: Experimental (points) and theoretical calculated (full line) PA amplitude (a) and phase difference (b) spectra of PbTe doped with 1.7 at $\% \mathrm{Au}$.

level in enhancing the thermoelectric power factor by the second mechanism depends a lot on the degree of localization of the electrons in the impurity states [29].

It has been also shown that $\mathrm{PbSe}$ doped with $\mathrm{Au}$ is a good candidate for $p$-type thermoelectric materials because of resonance states and a local increase of the DOS compared with $\mathrm{PbSe}$ doped with $\mathrm{Na}$ [28]. Also, knowing that the effects of the same impurities are very similar in both $\mathrm{PbSe}$ and $\mathrm{PbTe}$ and that Seebeck coefficient is almost doubled by doping $\mathrm{PbSe}$ with 3.125 at\% Au while the electrical conductivity then decreases one should expect that $\mathrm{PbTe}$ doped with $\mathrm{Au}$ is very promising material for thermoelectric applications.

\section{Conclusion}

Analyzing far infrared optical spectra and also photoacoustic ones for $\mathrm{PbTe}$ doped with either $\mathrm{Au}$ or $\mathrm{Cu}$, we could conclude that the sample with high concentration of $\mathrm{Au}$ in $\mathrm{PbTe}$ (about 3.3 at $\% \mathrm{Au}$ ) has the highest value of the free electron mobility and the lowest electron carrier concentration and the lowest frequency of the plasma minima. The samples of $\mathrm{PbTe}$ doped with $\mathrm{Cu}$ behave quite the opposite where the obtained experimental results for $\mathrm{PbTe}$ doped with 0.23 at $\% \mathrm{Cu}$ had the smallest carrier concentration, less than $10^{18} \mathrm{~cm}^{-3}$, and rather high free electron mobility, about $4500 \mathrm{~cm}^{2} / \mathrm{Vs}$, and the smallest plasma frequency as well. This suggests that 


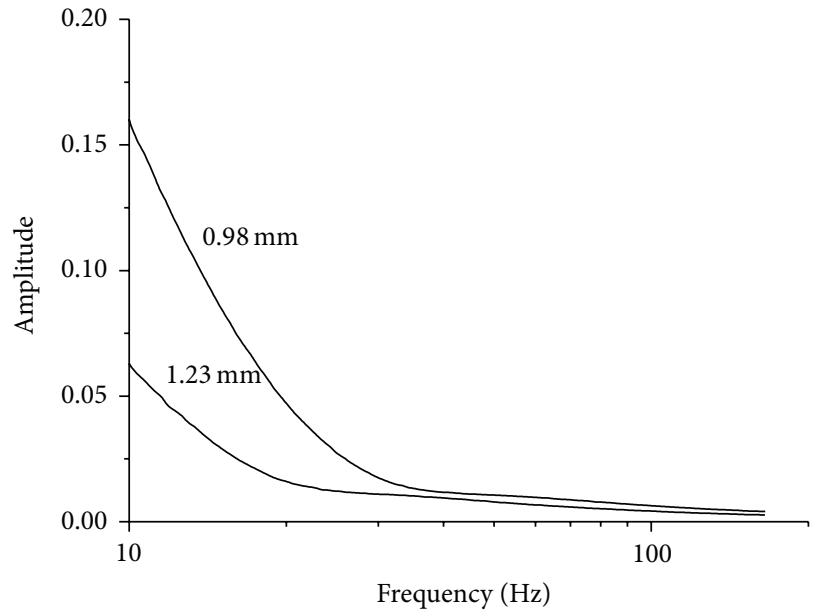

(a)

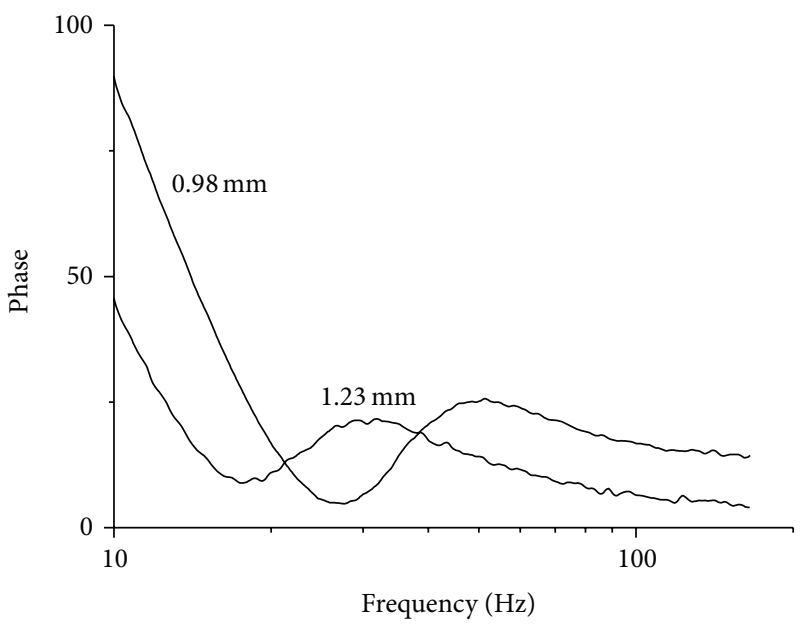

(b)

Figure 11: PA amplitude (a) and phase spectra (b) for PbTe doped with 1.7 at $\% \mathrm{Cu}$ for two different sample thicknesses.

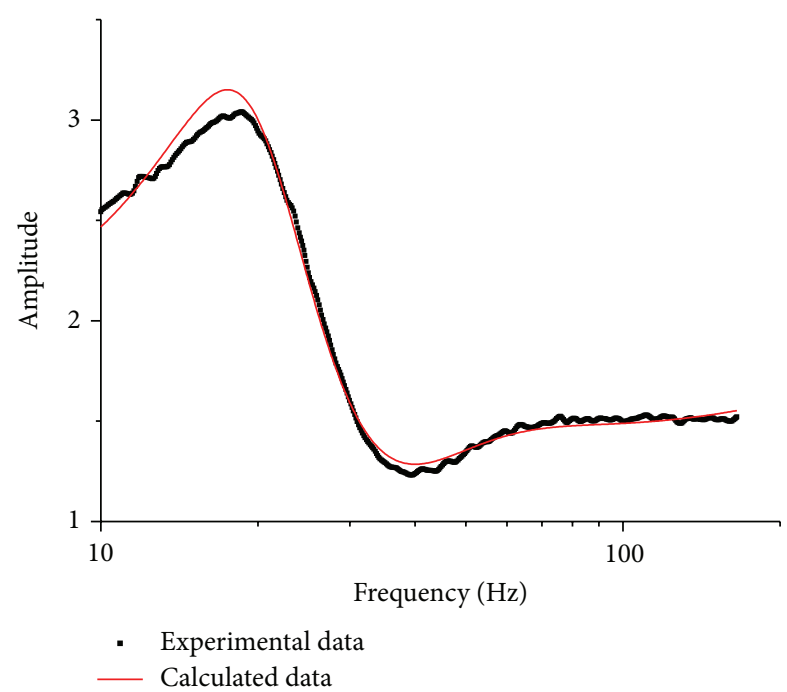

(a)

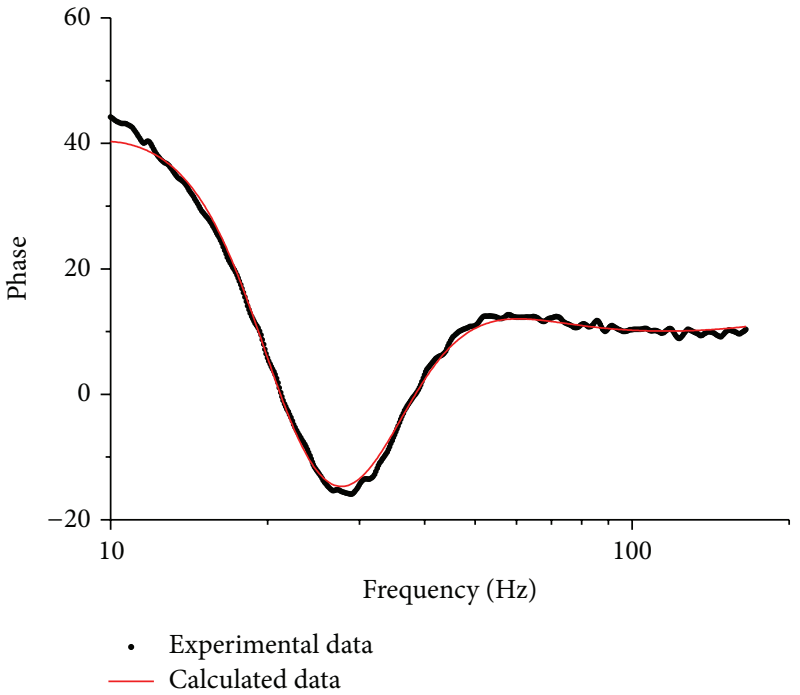

(b)

Figure 12: Experimental (points) and theoretically calculated (full line) PA amplitude (a) and phase difference (b) spectra of PbTe doped with 1.7 at\% Cu.

the smallest content of $\mathrm{Cu}$ atoms establishes a localized state that overlaps with either the conduction or the valence band of $\mathrm{PbTe}$. Knowing that $\mathrm{PbSe}$ doped with $\mathrm{Au}$ has the properties of a promising $p$-type thermoelectric material [28] and also knowing that the effect of the same impurity are very similar in both $\mathrm{PbSe}$ and $\mathrm{PbTe}$, one can expect that $\mathrm{PbTe}$ doped with $\mathrm{Au}$ is a very promising material for thermoelectric application. That is proved in this paper with the results obtained with measurements of FTIR and photoacoustic properties for PbTe doped with Au. PbTe is still one of the leading thermoelectric materials because of its low thermal conductivity. The longitudinal acoustic-transverse optic anharmonic coupling is likely to play a central role in explaining the low thermal conductivity of $\mathrm{PbTe}$ [29].

\section{Conflict of Interests}

The authors declare that there is no conflict of interests regarding the publication of this paper.

\section{Acknowledgment}

This work was performed as part of Projects III45007 and III45014 financed by the Ministry for Science and Education of the Republic of Serbia.

\section{References}

[1] E. Gamarekian, First Atom Battery Developed by U.S. Washington Post A1, 1959. 
[2] Y. Pei, A. LaLonde, S. Iwanaga, and G. J. Snyder, "High thermoelectric figure of merit in heavy hole dominated PbTe," Energy \& Environmental Science, vol. 4, no. 6, pp. 2085-2089, 2011.

[3] Y. Pei, A. D. LaLonde, H. Wang, and G. J. Snyder, "Low effective mass leading to high thermoelectric performance," Energy \& Environmental Science, vol. 5, no. 7, pp. 7963-7969, 2012.

[4] P. M. Nikolic, "Electrical and optical properties of PbTe-SnTe alloys," in Proceedings of the 9th Conference on Electronics, Telecommunications, Automation and Nuclear Physics (ETAN '64), Belgrade, Serbia, 1964.

[5] P. M. Nikolic, "Optical energy gaps, lattice parameters and solubility limits of solid solutions of SnSe and GeSe in PbTe, and GeSe in SnTe," British Journal of Applied Physics, vol. 16, no. 8, pp. 1075-1079, 1965.

[6] P. M. Nikolic, "Optical energy gaps of PbSe-SnTe, PbSe-SnSe, $\mathrm{PbTe}-\mathrm{SnTe}$ and PbTe-SnSe," British Journal of Applied Physics, vol. 18, no. 7, pp. 897-903, 1967.

[7] A. J. Strauss, "Metallurgical and electronic properties of Pb1xSnxTe, Pbl-xSnxSe and other IV-VI alloys," Transactions of the Metallurgical Society of AIME, vol. 242, pp. 354-365, 1968.

[8] B. A. Akimov, N. Brandt, L. I. Riabova, and D. R. Khokhlov, "A perspective alternative for modern photosensitive detectors of infrared radiation," Perspektivnye Materialy, no. 4, pp. 5-20, 2003.

[9] Z. Dashevsky, S. Shusterman, M. P. Dariel, and I. Drabkin, "Thermoelectric efficiency in graded indium-doped PbTe crystals," Journal of Applied Physics, vol. 92, no. 3, pp. 1425-1430, 2002.

[10] D. J. Singh, "Doping-dependent thermopower of PbTe from Boltzmann transport calculations," Physical Review B, vol. 81, Article ID 195217, 2010.

[11] A. Svane, N. E. Christensen, M. Cardona, A. N. Chantis, M. van Schilfgaarde, and T. Kotani, "Quasiparticle self-consistent GW calculations for PbS, PbSe, and PbTe: band structure and pressure coefficients," Physical Review B, vol. 81, no. 24, Article ID 245120, 2010.

[12] K. Hoang, S. D. Mahanti, and M. G. Kanatzidis, "Impurity clustering and impurity-induced bands in PbTe-, SnTe-, and GeTe-based bulk thermoelectrics," Physical Review B, vol. 81, Article ID 115106, 15 pages, 2010.

[13] A. J. Rosenberg, R. Grierson, J. C. Woolley, and P. M. Nikolić, "Solid solutions of CdTe and InTe in PbTe and SnTe I. Crystal chemistry," Transactions of the Metallurgical Society of AIME, vol. 230, pp. 342-350, 1964.

[14] K. Weiser, "Doping of PbTe with Group-III elements: an ionic lattice approach," Physical Review B, vol. 23, pp. 2741-2751, 1981.

[15] P. M. Nikolic, K. M. Paraskevopoulos, G. Zachariadis et al., "Far infrared study of local impurity modes of Boron-doped PbTe," Journal of Materials Science, vol. 47, no. 5, pp. 2384-2389, 2012.

[16] V. Tetyorkin and S. Movchan, "Semiconductor physics," Quantum Electronics and Optoelectronics, vol. 3, pp. 300-303, 2000.

[17] N. Romcevic, D. Stojanović, M. Romcevic, and D. R. Khokhlov, "Far-infrared and galvanomagnetic study of gallium doped PbTe," Journal of Alloys and Compounds, vol. 460, no. 1-2, pp. 13-19, 2008.

[18] J. Q. Li, S. P. Li, Q. B. Wang, L. Wang, F. S. Liu, and W. Q. Ao, "Effect of Ce-doping on thermoelectric properties in PbTe alloys prepared by spark plasma sintering," Journal of Electronic Materials, vol. 40, no. 10, pp. 2063-2068, 2011.

[19] S. Ahmad, S. D. Mahanti, K. Hoang, and M. G. Kanatzidis, "Ab initio studies of the electronic structure of defects in PbTe," Physical Review B, vol. 74, Article ID 155205, 13 pages, 2006.
[20] J. Capps, B. Ma, T. Drye et al., "The effect of Ag concentration on the structural, electrical and thermal transport behavior of $\mathrm{Pb}: \mathrm{Te}: \mathrm{Ag}: \mathrm{Se}$ mixtures and improvement of thermoelectric performance via Cu doping," Journal of Alloys and Compounds, vol. 509, no. 5, pp. 1544-1549, 2011.

[21] B. A. Akimov, L. I. Ryabova, S. M. Chudinov, and O. B. Yatsenko, "Semiconductor-metal-semiconductor transitions in Pb1-xSnxTe in alloys under pressure," Soviet Physics Semiconductors-USSR, vol. 13, pp. 752-759, 1979.

[22] F. Gervais and B. Piriou, "Temperature dependence of transverse- and longitudinal-optic modes in $\mathrm{TiO}_{2}$ (rutile)," Physical Review B, vol. 10, no. 4, pp. 1642-1654, 1974.

[23] A. A. Kukharskii, "Plasmon-phonon coupling in GaAs," Solid State Communications, vol. 13, no. 11, pp. 1761-1765, 1973.

[24] D. M. Roessler, "Kramers-Kronig analysis of non-normal incidence reflection," British Journal of Applied Physics, vol. 16, no. 9, pp. 1359-1366, 1965.

[25] T. S. Moss, T. D. F. Hawkins, and G. J. Burrell, "Use of plasma edge reflection measurements in the study of semiconductors," Journal of Physics C: Solid State Physics, vol. 1, no. 5, pp. 14351446, 1968.

[26] P. M. Nikolić, S. S. Vujatović, D. M. Todorović et al., “Thermal and electronic transport properties of single crystal $\mathrm{PtSb}_{2}$ obtained by the photoacoustic method," Japanese Journal of Applied Physics, vol. 36, no. 3, pp. 1006-1011, 1997.

[27] A. Rosencwaig and A. Gershow, "Theory of the photoacoustic effect with solids," Journal of Applied Physics, vol. 46, p. 64, 1976.

[28] H. Peng, J. H. Song, M. G. Kanatzidis, and A. J. Freeman, "Electronic structure and transport properties of doped PbSe," Physical Review B, vol. 84, Article ID 125207, 2011.

[29] O. Delaire, J. Ma, K. Marty et al., "Giant anharmonic phonon scattering in PbTe," Nature Materials, vol. 10, no. 8, pp. 614-619, 2011. 

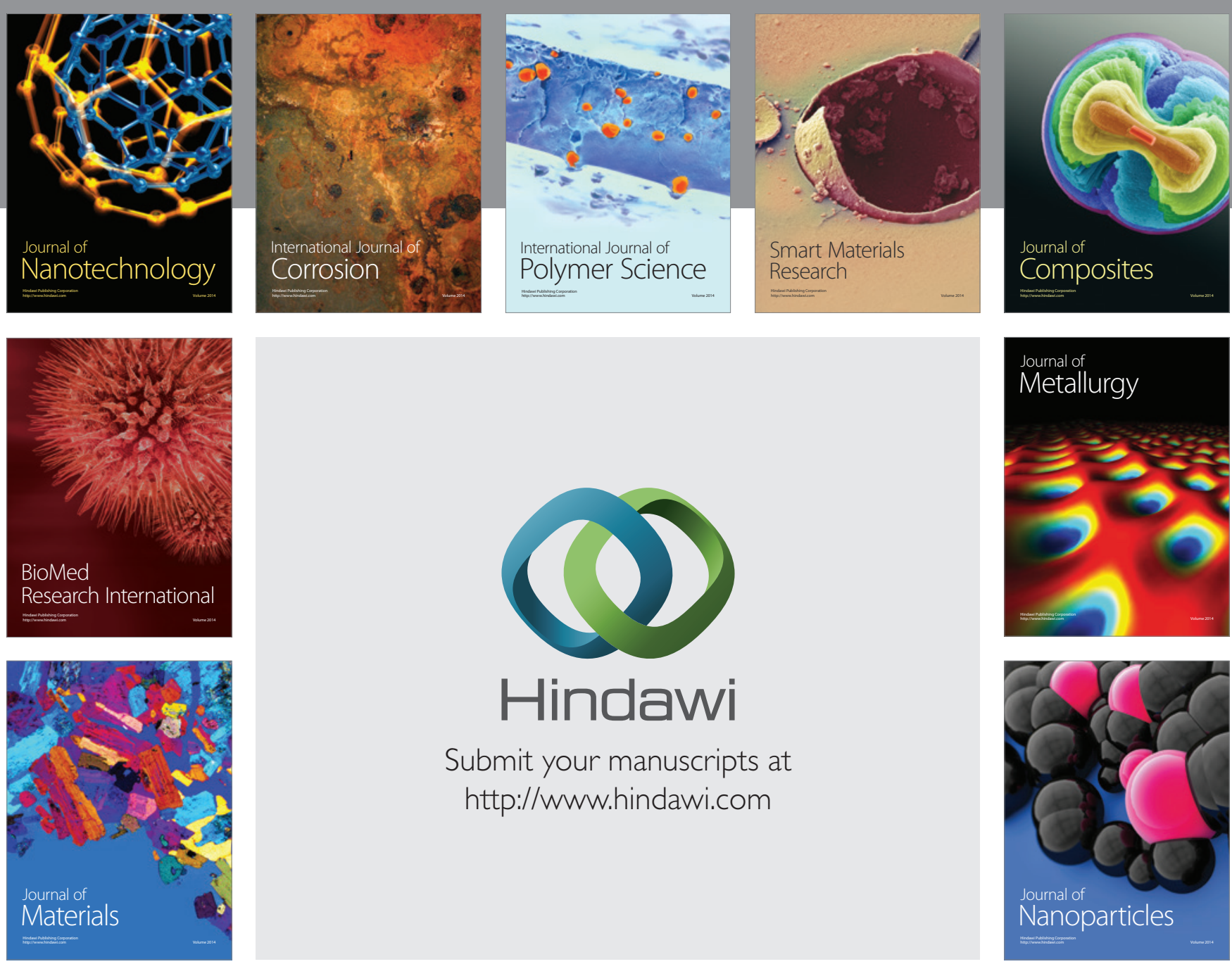

Submit your manuscripts at http://www.hindawi.com
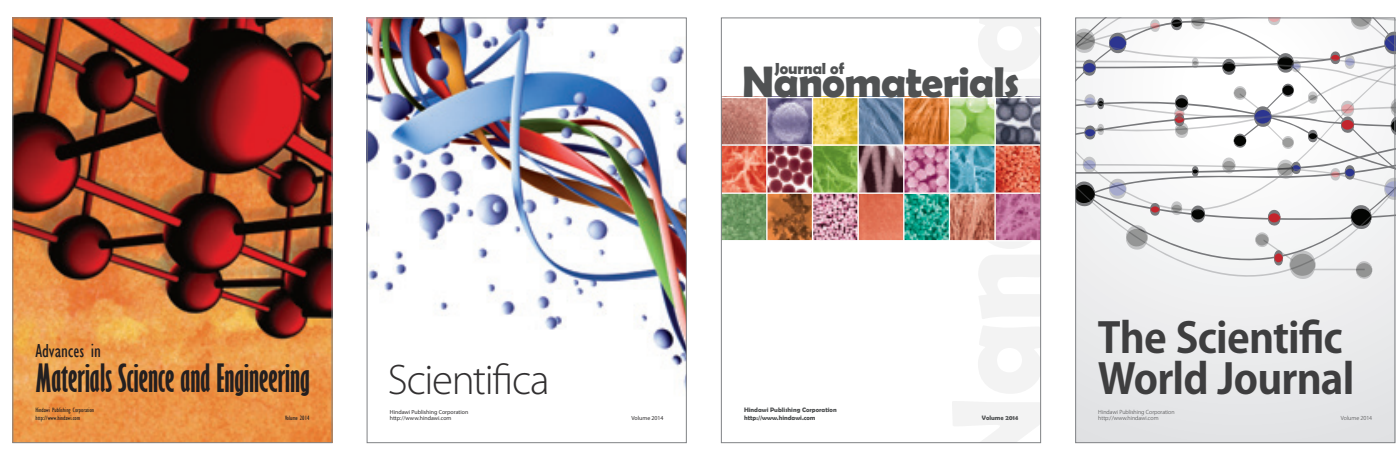

\section{The Scientific World Journal}
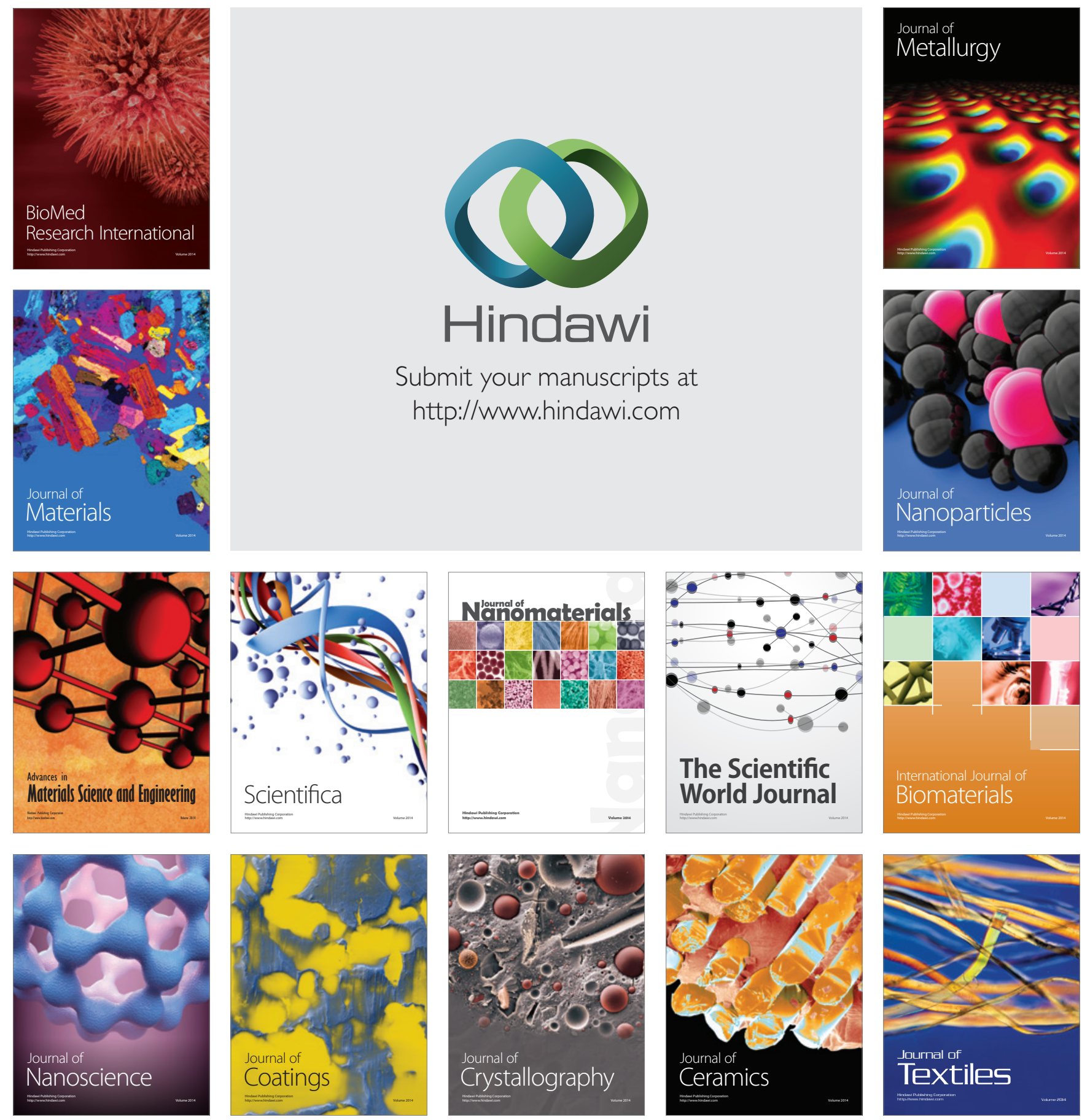